\title{
EFEITO DE NÍVEIS DE FÓSFORO NÃO-FÍTICO E DE FITASE SOBRE A TíBIA DE FRANGOS DE CORTE
}

\section{Effect of nonphytate phosphorus and phytase levels on broiler tibia}

\author{
OLIVEIRA, M.C'.; SILVA, D. ${ }^{1}$; LOCH, F.C ${ }^{1}$; LAURENTIZ, A.C. ${ }^{2}$; JUNQUEIRA, O.M. ${ }^{3}$
}

${ }^{1}$ Universidade de Rio Verde.

${ }^{2}$ UNESP - Ilha Solteira.

${ }^{3}$ UNESP - Jaboticabal.

Endereço para correspondência: Maria Cristina de Oliveira - cristina@fesurv.br.

\section{RESUMO}

Avaliou-se o efeito de níveis de fósforo não-fítico (FNF) e fitase sobre a morfometria e a densidade de tíbia de frangos. Foram utilizadas 1200 aves em delineamento inteiramente casualizado em arranjo fatorial $4 \times 3$ (níveis de FNF $\mathrm{x}$ níveis de fitase), com quatro repetições. Os níveis de FNF, em cada fase, foram 0,$45 ; 0,37 ; 0,29$ e $0,21 \%$ na fase inicial; 0,$41 ; 0,33 ; 0,25$ e $0,17 \%$ na de crescimento e 0,$37 ; 0,29 ; 0,21$ e $0,13 \%$ na final. Os níveis de fitase foram 0, 500 e 1000 UFT/kg de ração. Não houve efeito sobre diâmetro das tíbias aos 21 dias. Tíbias com menor peso, comprimento e densidade de diáfise, epífise distal e média, e densidade de epífise proximal resultaram da redução do FNF de 0,37 para $0,29 \%$ e de 0,29 para $0,21 \%$, respectivamente. A inclusão de $500 \mathrm{UFT} / \mathrm{kg}$ de ração melhorou o comprimento e a densidade da diáfise das tíbias, independente dos níveis de FNF. Pode-se adotar dieta FNF nas fases inicial, crescimento e final de 0,37, 0,33 e 0,29\%, respectivamente, suplementadas com 1000 UFT/kg de ração, de um a 42 dias, sem comprometer a qualidade óssea.

Palavras-chave: aditivos, enzimas, qualidade óssea.

\section{ABSTRACT}

It was evaluated the effect of nonphytate phosphorus (NNP) and phytase on broiler tibia. One thousand and two hundred chicks were allocated in a completely randomized design and factorial arrangement $4 \times 3$ (NPP $\times$ phytase levels), with four replicates. NPP levels, at each phase, were $0.45,0.37,0.29$ and $0.21 \%$ - initial, $0.41,0.33,0.25$ and $0.17 \%$ - growth, and $0.37,0.29,0.21$ and $0.13 \%$ - withdrawal. Phytase levels were 0,500 and $1000 \mathrm{FTU} / \mathrm{kg}$ of diet. There was no effect on diameter at 21 days of age. Tibia with lower weight, length and diaphysis, distal epiphysis and average densities e proximal epiphysis density resulted from NPP reduction from 0.37 to $0.29 \%$ and from 0.29 to $0.21 \%$, respectively. Inclusion of $500 \mathrm{FTU} / \mathrm{kg}$ of phytase improved length and diaphysis density of the tibia, independent of NPP levels. Diets with NPP, at initial, growth and final phases, of $0.37,0.33$ and $0.29 \%$, respectively, supplemented with $1000 \mathrm{FTU} / \mathrm{kg}$ of phytase, can be used with no negative effect on bone quality in broilers.

Key words: additives, bone quality, enzymes. 


\section{INTRODUÇÃO}

O fósforo $(P)$ é um mineral essencial para o crescimento e desenvolvimento dos ossos nos animais. Além disso, esse mineral também desempenha um papel crítico no metabolismo de carboidratos, proteínas e lipídios, principalmente na fosforilação oxidativa (Hatten et al., 2001). O não fornecimento de quantidades adequadas de $\mathrm{P}$ pode resultar em pior desempenho, deformidades ósseas, maior condenação de carcaça e alta mortalidade (Panda et al., 2007).

O ácido fítico, abundante em grãos e sementes oleaginosas, é a principal forma de armazenamento de $P$ nesses alimentos. A molécula de ácido fítico tem alto teor de $\mathrm{P}(28,2 \%)$ e, uma vez que a maior parte da dieta de frangos consiste de ingredientes vegetais, $\mathrm{O} P$ do ácido fítico assume considerável importância nutricional. Entretanto, a capacidade da ave em utilizar o P fítico é baixa, devido a quantidades insuficientes ou ausência de secreção de fitase endógena (Wu et al., 2004). O ácido fítico também se liga a outros minerais, tais como $\mathrm{Ca}, \mathrm{Fe}, \mathrm{Zn}, \mathrm{Mn}$, $\mathrm{Cu}$ e $\mathrm{Co}$, podendo reduzir a disponibilidade desses minerais (Shelton e Southern, 2006).

Devido à presença do ácido fítico, a disponibilidade de $P$ em alimentos comumente usados para aves é de, aproximadamente, 30 a 40\% (NRC, 1994; Rostagno et al., 2005). Sendo assim, fósforo inorgânico $(\mathrm{Pi})$ é adicionado às dietas de monogástricos para compensar a utilização ineficiente do $\mathrm{P}$ fítico (Jendza et al., 2006). Entretanto, deve-se considerar que o $\mathrm{P}$ é o terceiro nutriente mais caro em dietas avícolas, após proteína e nutrientes fornecedores de energia (Biehl et al., 1998).

As pesquisas mais recentes têm sugerido que as recomendações de fósforo não-fítico (FNF) do NRC (1994) excedem as exigências dos frangos de corte (Dhandu e Angel, 2003; Angel et al., 2005b). A inclusão da fitase, enzima que hidrolisa o ácido fítico, em dietas avícolas pode resultar em mais $P$ fítico disponível para ser absorvido pelo animal. Haveria também a diminuição da necessidade de suplementação com $\mathrm{Pi}$ uma vez que o teor de $\mathrm{P}$ dietético seria reduzido (Applegate et al., 2003; Angel et al., 2005a).

O teor de minerais dos ossos tem sido extensivamente usado como critério para avaliar as exigências de $P$ por ser um indicador mais sensível da suficiência de $P$ do que a taxa de crescimento (Dhandu e Angel, 2003). Porém, tanto o teor mineral como a densitometria óssea podem ser usados para determinar a mineralização óssea, sendo que a densitometria resulta em menor trabalho e em menor gasto de tempo comparado com a tradicional metodologia da matéria mineral dos ossos (Angel et al., 2004).

Nesse sentido, esse experimento foi realizado para avaliar o efeito de níveis dietéticos de FNF e da enzima fitase sobre o peso, a morfometria e a densidade de tíbias de frangos de corte aos 21 e 42 dias de idade.

\section{MATERIAL E MÉTODOS}

Foram utilizados 1200 pintos de corte machos, da linhagem Cobb, com um dia de idade, alojados em galpão de alvenaria dividido em boxes de 2,8 x 1,6m (área total de $4,48 \mathrm{~m}^{2}$ ). O manejo adotado para as fases de criação seguiu as recomendações do manual da linhagem.

$O$ delineamento experimental foi inteiramente casualizado em fatorial $4 \times 3$ (quatro níveis de FNF $x$ três níveis de fitase), com quatro repetições de 25 aves cada. Os níveis de fósforo não-fítico, em cada fase, foram de 0,$45 ; 0,37 ; 0,29$ e $0,21 \%$ na fase inicial ( 1 a 21 dias); 0,41 ; 0,$33 ; 0,25$ e $0,17 \%$ na fase de crescimento (22 a 35 dias) e de 0,37; 0,29; 0,21 e $0,13 \%$ na fase final ( 36 a 42 dias de idade). Assim a redução dos níveis de fósforo não- 
fítico das dietas, em cada fase de criação, foi de 18,36 e $54 \%$ na fase inicial; 19,38 e $58 \%$ na de crescimento; 21,43 e $64 \%$ na final. Os níveis de fitase utilizados foram 0 , 100 e 200g/tonelada, garantindo 0,500 e 1000 UFT/kg de ração.

Os tratamentos foram os seguintes: $\mathrm{T}_{1}$ 0,45\%, 0,41\% e 0,37\% FNF; $\mathrm{T}_{2}-\mathrm{T} 1+500$ UFT/kg de ração; $\mathrm{T}_{3}-\mathrm{T} 1+1000 \mathrm{UFT} / \mathrm{kg}$ de ração; $T_{4}-0,37 \%, 0,33 \%$ e $0,29 \% \mathrm{FNF}$; $\mathrm{T}_{5}-\mathrm{T} 4+500 \mathrm{UFT} / \mathrm{kg}$ de ração; $\mathrm{T}_{6}-\mathrm{T} 4$ + $1000 \mathrm{UFT} / \mathrm{kg}$ de ração; $\mathrm{T}_{7}-0,29 \%, 0,25 \%$ e $0,21 \% \mathrm{FNF} ; \mathrm{T}_{8}-\mathrm{T} 7+500 \mathrm{UFT} / \mathrm{kg}$ de ração; $T_{9}-T 7+1000$ UFT/kg de ração; $T_{10}$ $-0,21 \%, 0,17 \%$ e $0,13 \%$ FNF; $\mathrm{T}_{11}-\mathrm{T} 10+$ $500 \mathrm{UFT} / \mathrm{kg}$ de ração e $\mathrm{T}_{12}-\mathrm{T} 10+1000$ UFT/kg de ração.

A enzima fitase utilizada foi a Natuphos $5.000^{\circledR}$, obtida por intermédio da fermentação por fungos Aspergillus niger, contendo atividade inicial mínima, declarada pelo fabricante, de $5.000 \mathrm{UFT} / \mathrm{g}$ do produto. As dietas experimentais fareladas eram isonutritivas e foram formuladas de acordo as recomendações nutricionais e a composição dos ingredientes de Rostagno et al. (2005), exceto para os valores de fósforo não-fítico.

Aos 21 e 42 dias de idade, 48 aves, quatro por tratamento, foram abatidas por deslocamento cervical e delas foram retiradas as tíbias. Estas tíbias, após serem extraídas, tiveram a remoção dos tecidos aderentes. As tíbias esquerdas foram utilizadas para obtenção do peso e para a morfometria (comprimento e diâmetro) obtida com paquímetro manual e as tíbias direitas foram utilizadas para a determinação da densidade óssea.

Para a densidade óssea fez-se uso de imagens radiográficas das tíbias e, como referencial densitométrico, utilizou-se uma escala de alumínio (alumínio 6063 ABNT) com 12 degraus. $O$ primeiro degrau tinha espessura de $0,5 \mathrm{~mm}$ e do segundo até o décimo degrau, a espessura aumentou de $0,5 \mathrm{em} 0,5 \mathrm{~mm}$ sucessivamente. $O 11^{\circ}$ degrau tinha espessura de $6 \mathrm{~mm}$ e $012^{\circ}$ de $8 \mathrm{~mm}$. A área de cada degrau era de $5 \times 25$ $\mathrm{mm}$. A escala de alumínio foi radiografada juntamente com as tíbias. Um aparelho de raio-X convencional foi calibrado para 44 $k V p$ e 4 mAs, com um metro de distância entre o foco e o filme. Para a determinação da densidade óssea, as imagens foram digitalizadas em scanner HP Scanjet 4C equipado com um adaptador para digitalizar imagens radiográficas. Após a digitalização, as imagens foram transferidas para um computador e analisadas por meio do Programa ImagePro Media Cybernetics (versão 4.1.0). A densidade foi determinada nas epífises proximal e distal, e na diáfise de cada osso, sendo estes valores comparados com a densidade óptica da escala de alumínio e expressos em $\mathrm{mm}$ de Alumínio ( $\mathrm{mm} \mathrm{Al}$ ) (Louzada, 1994). Calculou-se também a densidade média dos três valores obtidos para as densidades das epífises proximal e distal e da diáfise.

Os resultados obtidos foram submetidos à análise de variância por meio do programa SAEG (UFV, 2001) e as médias comparadas pelo teste de Tukey a $5 \%$ de probabilidade.

\section{RESULTADOS E DISCUSSÃo}

Não houve efeito $(P>0,05)$ dos tratamentos sobre o diâmetro das tíbias aos 21 dias de idade (Tabela 1). Entretanto, a redução dos níveis de FNF para $0,29 \%$ ou menos resultou em tíbias com menores $(P<0,05)$ peso, comprimento e menores valores de densidade nas epífises proximal e distal, na diáfise e de densidade média do osso. A inclusão de $500 \mathrm{UFT} / \mathrm{kg}$ de ração melhorou $(P<0,05) 0$ comprimento e a densidade da diáfise das tíbias, independente dos níveis de FNF.

O nível de $0,37 \%$ de FNF foi suficiente para manter normais 0 peso e 0 comprimento, bem como a densidade das tíbias durante a fase inicial de criação. Nessa fase, o P é utilizado em larga escala, não só para o crescimento do tecido ósseo, mas também como constituinte de ácidos 
Tabela 1 - Peso e morfometria de tíbias de frangos aos 21 dias de idade, alimentados com dietas contendo níveis de fósforo não-fítico (FNF) e de fitase

\begin{tabular}{|c|c|c|c|c|c|c|c|}
\hline \multirow[t]{2}{*}{ Parâmetro } & \multirow{2}{*}{$\begin{array}{l}\text { Fitase } \\
(\mathrm{U} / \mathrm{kg})\end{array}$} & \multicolumn{4}{|c|}{ FNF (\%) } & \multirow[t]{2}{*}{ Média } & \multirow{2}{*}{$\begin{array}{l}\text { CV } \\
(\%)\end{array}$} \\
\hline & & 0,45 & 0,37 & 0,29 & 0,21 & & \\
\hline \multirow{4}{*}{ Peso (g) } & 0 & 5,96 & 6,18 & 4,91 & 4,40 & 5,36 & \\
\hline & 500 & 6,51 & 5,76 & 5,83 & 5,07 & 5,79 & \\
\hline & 1000 & 6,16 & 6,32 & 5,52 & 4,93 & 5,73 & \\
\hline & Média & $6,21 \mathrm{a}$ & $6,08 a b$ & $5,42 b c$ & $4,80 \mathrm{c}$ & & 11,18 \\
\hline \multirow[t]{4}{*}{ Diâmetro (mm) } & 0 & 6,50 & 6,25 & 6,00 & 5,37 & 6,03 & \\
\hline & 500 & 6,00 & 5,75 & 6,00 & 5,75 & 5,87 & \\
\hline & 1000 & 6,25 & 6,12 & 6,00 & 5,62 & 6,00 & \\
\hline & Média & 6,25 & 6,04 & 6,00 & 5,58 & & 11,01 \\
\hline \multirow[t]{4}{*}{ Comprimento (mm) } & 0 & 73,00 & 72,75 & 68,87 & 63,37 & $69,50 \mathrm{~B}$ & \\
\hline & 500 & 75,25 & 72,25 & 71,75 & 67,87 & $71,78 A$ & \\
\hline & 1000 & 73,00 & 73,75 & 72,50 & 66,50 & $71,43 \mathrm{~A}$ & \\
\hline & Média & $73,75 a$ & $72,91 \mathrm{ab}$ & $71,04 b$ & $65,91 c$ & & 3,49 \\
\hline
\end{tabular}

Médias seguidas de letras diferentes, minúsculas nas linhas e maiúsculas nas colunas, diferem pelo teste de Tukey a $5 \%$ de probabilidade.

nucléicos, de compostos energéticos e de fosfolipídios encontrados nas membranas e também está envolvido em várias reações enzimáticas bem como no transporte de $\mathrm{O}_{2}$, como um constituinte de compostos fosfoglicerato (Drezner, 2002). Mesmo assim, a exigência de $P$ foi atendida com um nível abaixo do remendado na literatura, que é $0,45 \%$.

A densidade óssea é uma estimativa do teor de minerais por unidade de área ou volume (Nelson et al., 2000) e por isso, a redução dos níveis de FNF diminuiu a densidade das tíbias em aves que ingeriram dietas com 0,29 e $0,21 \%$ de FNF (Tabela 2). Pode-se inferir, então, que a taxa de mineralização também foi menor, sendo o nível de 0,37\% adequado também para a manutenção da densidade tibial na fase inicial.

A interação FNF $x$ fitase foi significativa para o comprimento das tíbias de aves com 42 dias de idade (Tabela 3). Aves que consumiram dietas sem fitase e com o menor nível de FNF avaliado, apresentaram tíbias menores. Porém, quando as dietas foram suplementadas com 500 ou 1000 UFT/kg de ração, as tíbias atingiram o comprimento obtido com o uso de rações com níveis adequados de FNF.
Para que o osso cresça, é necessária a presença de minerais em quantidades adequadas. Nesse aspecto, supõe-se que

a suplementação com fitase levou a um aumento na disponibilidade de $\mathrm{P}$ para absorção e posterior utilização para crescimento dos ossos.

A redução dos níveis de FNF resultou em menores $(P<0,05)$ peso e diâmetro médios. Nas fases de crescimento e final, os órgãos e tecidos já estão formados e o metabolismo dos nutrientes é dirigido principalmente para a deposição muscular, que é maior comparada com a fase inicial. Portanto, a exigência de $P$ nessa fase é menor, o que permitiu que níveis ainda menores de FNF pudessem ser utilizados sem que houvesse prejuízo no peso e diâmetro das tíbias. $\mathrm{O}$ diâmetro aumentou $(P<0,05) \mathrm{com}$ a inclusão de $500 \mathrm{UFT} / \mathrm{kg}$ de ração, resultado da liberação $P$ para que fosse absorvido e depositado no osso.

Não houve efeito $(P>0,05)$ da interação FNF $x$ fitase aos 42 dias de idade (Tabela 4). No entanto, os menores níveis de FNF resultaram em menores valores de densidade das epífises proximal e distal. A diminuição da densidade na epífise proximal ocorreu mesmo quando níveis mais altos de FNF foram usados, diferente do ocorrido na epífise distal. Isso ocorreu 
por que a epífise proximal é a região do osso que está submetida a maior pressão ocasionada pelo peso do corpo da ave. De acordo com Joakimsen et al. (1998) e UusiRasi et al. (2002), quanto maior o peso suportado pelo osso, maior o desenvolvimento e remodelagem óssea e, consequentemente, maior a massa óssea o que irá se refletir em maior densidade.

A inclusão de fitase melhorou $(P<0,05)$ a densidade da diáfise e a densidade média. Como já mencionado, o peso do corpo é um fator que estimula o desenvolvimento e manutenção da massa óssea, mas para que isso ocorra é necessário que haja minerais em quantidades suficientes $e$, nesse caso, foram necessárias 1000 UFT/kg de ração para que houvesse liberação de $\mathrm{P}$ suficiente para atender a demanda óssea.

Resultados semelhantes foram obtidos por Viveros et al. (2002) que estudaram dietas com níveis reduzidos de $\operatorname{FNF}(0,45$ a $0,24 \%$ ) suplementadas ou não com 500 $\mathrm{UFT} / \mathrm{kg}$ de ração e notaram que houve redução no peso da tíbia com os menores níveis de FNF e a suplementação de dietas com fitase melhorou o peso dos ossos. Já Kocabagli (2001) que relataram que a inclusão de 700 a 1500 UFT/kg de ração em dietas com níveis de $P$ reduzidos para frangos não afetou o peso, comprimento e diâmetro das tíbias.

Atia et al. (2000), ao avaliarem níveis de $\mathrm{Ca}$ e $\mathrm{P}$ em dietas para perus notaram que quando dietas suplementadas com 500

Tabela 2 - Densidade das tíbias de frangos aos 21 dias de idade, alimentados com dietas com níveis de fósforo não-fítico (FNF) e de fitase

\begin{tabular}{|c|c|c|c|c|c|c|c|}
\hline \multirow{2}{*}{$\begin{array}{l}\text { Densidade } \\
(\mathrm{mm} \mathrm{Al})\end{array}$} & \multirow{2}{*}{$\begin{array}{l}\text { Fitase } \\
(\mathrm{U} / \mathrm{kg})\end{array}$} & \multicolumn{4}{|c|}{ FNF (\%) } & \multirow[t]{2}{*}{ Média } & \multirow{2}{*}{$\begin{array}{l}\text { CV } \\
(\%)\end{array}$} \\
\hline & & 0,45 & 0,37 & 0,29 & 0,21 & & \\
\hline \multirow[t]{4}{*}{ Epífise proximal } & 0 & 1,90 & 1,67 & 1,47 & 1,81 & 1,71 & \\
\hline & 500 & 2,13 & 1,74 & 1,44 & 1,62 & 1,73 & \\
\hline & 1000 & 1,71 & 1,95 & 1,58 & 1,51 & 1,69 & 15,15 \\
\hline & Média & $1,91 \mathrm{a}$ & $1,79 a$ & $1,64 a b$ & $1,50 b$ & & \\
\hline \multirow[t]{4}{*}{ Diáfise } & 0 & 2,74 & 2,58 & 1,89 & 1,62 & $2,21 B$ & \\
\hline & 500 & 3,07 & 2,56 & 2,48 & 1,95 & $2,52 \mathrm{~A}$ & \\
\hline & 1000 & 2,67 & 2,94 & 2,24 & 1,98 & $2,46 \mathrm{~A}$ & \\
\hline & Média & $2,83 a$ & $2,69 a$ & $2,20 b$ & $1,85 c$ & & 12,39 \\
\hline \multirow[t]{4}{*}{ Epífise distal } & 0 & 1,87 & 1,65 & 1,27 & 1,48 & 1,57 & \\
\hline & 500 & 1,88 & 1,62 & 1,38 & 1,44 & 1,58 & \\
\hline & 1000 & 1,78 & 1,76 & 1,52 & 1,32 & 1,59 & \\
\hline & Média & $1,84 a$ & $1,67 a$ & $1,39 b$ & $1,42 b$ & & 14,15 \\
\hline \multirow[t]{4}{*}{ Densidade média } & 0 & 2,16 & 1,96 & 1,54 & 1,63 & 1,82 & \\
\hline & 500 & 2,35 & 1,9 & 1,76 & 1,67 & 1,94 & \\
\hline & 1000 & 2,05 & 2,21 & 1,77 & 1,60 & 1,91 & \\
\hline & Média & $2,19 a$ & $2,05 a$ & $1,69 b$ & $1,63 b$ & & 11,74 \\
\hline
\end{tabular}

Médias seguidas de letras diferentes, minúsculas nas linhas e maiúsculas nas colunas, diferem pelo teste de Tukey a $5 \%$ de probabilidade. 
Tabela 3 - Peso e morfometria de tíbias de frangos, com 42 dias de idade, alimentados com dietas com níveis de fósforo não-fítico e de fitase

\begin{tabular}{|c|c|c|c|c|c|c|c|}
\hline \multirow[t]{2}{*}{ Parâmetro } & \multirow{2}{*}{$\begin{array}{l}\text { Fitase } \\
(\mathrm{U} / \mathrm{kg})\end{array}$} & \multicolumn{4}{|c|}{ FNF (\%) } & \multirow[b]{2}{*}{ Média } & \multirow[b]{2}{*}{$\begin{array}{l}\text { CV } \\
(\%)\end{array}$} \\
\hline & & $\begin{array}{c}0,45- \\
0,41- \\
0,37\end{array}$ & $\begin{array}{c}0,37- \\
0,33- \\
0,29\end{array}$ & $\begin{array}{c}0,29- \\
0,25- \\
0,21\end{array}$ & $\begin{array}{c}0,21- \\
0,17-0,13\end{array}$ & & \\
\hline \multirow[t]{4}{*}{ Peso (g) } & 0 & 14,50 & 14,90 & 17,96 & 10,67 & 14,51 & \\
\hline & 500 & 14,79 & 14,39 & 13,82 & 13,07 & 14,02 & \\
\hline & 1000 & 15,97 & 16,10 & 15,16 & 13,30 & 15,13 & \\
\hline & Média & $15,09 a$ & $15,13 a$ & $15,65^{\underline{a}}$ & $12,35 b$ & & 15,53 \\
\hline \multirow[t]{4}{*}{ Diâmetro (mm) } & 0 & 8,37 & 8,62 & 8,12 & 7,37 & $8,12 \mathrm{~B}$ & \\
\hline & 500 & 8,87 & 8,50 & 8,50 & 7,87 & $8,43 \mathrm{AB}$ & \\
\hline & 1000 & 9,25 & 9,37 & 8,25 & 8,37 & $8,81 \mathrm{~A}$ & \\
\hline & Média & $8,83 a$ & $8,83 a$ & $8,29 b$ & $7,87 \mathrm{~b}$ & & 9,24 \\
\hline \multirow{4}{*}{$\begin{array}{l}\text { Comprimento } \\
(\mathrm{mm})\end{array}$} & 0 & 101,25Aa. & 100,37Aa. & 102,50Aa. & 85,47B & 97,40 & \\
\hline & 500 & 100,37Aa. & 102,00Aa. & 97,25Aa. & 97,62Aa. & 99,31 & \\
\hline & 1000 & 101,87Aa. & 101,00Aa. & 98,62Aa. & 96,12Aa. & 99,40 & \\
\hline & Média & 101,16 & 101,12 & 99,45 & 93,07 & & 4,05 \\
\hline
\end{tabular}

Tabela 4 - Densidade das tíbias de frangos aos 42 dias de idade alimentados com dietas com níveis de fósforo não-fítico e de fitase

\begin{tabular}{|c|c|c|c|c|c|c|c|}
\hline \multirow{2}{*}{$\begin{array}{l}\text { Densidade } \\
(\mathrm{mm} \mathrm{Al})\end{array}$} & \multirow{2}{*}{$\begin{array}{l}\text { Fitase } \\
(\mathrm{U} / \mathrm{kg})\end{array}$} & \multicolumn{4}{|c|}{ FNF (\%) } & \multirow[b]{2}{*}{ Média } & \multirow[b]{2}{*}{$\begin{array}{l}\text { CV } \\
\text { (\%) }\end{array}$} \\
\hline & & $\begin{array}{c}0,45- \\
0,41-0,37\end{array}$ & $\begin{array}{c}0,37- \\
0,33-0,29\end{array}$ & $\begin{array}{c}0,29- \\
0,25-0,21\end{array}$ & $\begin{array}{c}0,21- \\
0,17-0,13\end{array}$ & & \\
\hline \multirow[t]{4}{*}{ Epífise proximal } & 0 & 2,63 & 2,45 & 2,54 & 2,30 & 2,48 & \\
\hline & 500 & 2,72 & 2,10 & 1,93 & 2,60 & 2,34 & \\
\hline & 1000 & 2,94 & 2,36 & 2,42 & 2,14 & 2,45 & \\
\hline & Média & $2,76 a$ & $2,30 b$ & $2,30 b$ & $2,35 b$ & & 15,5 \\
\hline \multirow[t]{4}{*}{ Diáfise } & 0 & 2,78 & 3,28 & 2,85 & 2,44 & $2,84 \mathrm{~B}$ & \\
\hline & 500 & 2,47 & 2,85 & 2,56 & 2,42 & $2,57 \mathrm{~B}$ & \\
\hline & 1000 & 3,66 & 3,26 & 4,00 & 3,09 & $3,50 \mathrm{~A}$ & \\
\hline & Média & 2,97 & 3,13 & 3,14 & 2,65 & & 16,5 \\
\hline \multirow[t]{4}{*}{ Epífise distal } & 0 & 2,22 & 2,35 & 2,85 & 1,63 & 2,26 & \\
\hline & 500 & 1,98 & 2,01 & 1,73 & 1,90 & 1,91 & \\
\hline & 1000 & 2,31 & 2,03 & 2,41 & 1,95 & 2,17 & \\
\hline & Média & $2,17 a$ & $2,13 a$ & $2,33 a$ & $1,83 b$ & & 19,3 \\
\hline \multirow[t]{4}{*}{ Dens. média } & 0 & 2,51 & 2,69 & 2,75 & 2,12 & $2,51 \mathrm{~B}$ & \\
\hline & 500 & 2,39 & 2,32 & 2,04 & 2,30 & $2,26 B$ & \\
\hline & 1000 & 2,97 & 2,54 & 2,94 & 2,38 & $2,71 \mathrm{~A}$ & \\
\hline & Média & 2,62 & 2,52 & 2,58 & 2,27 & & 13,6 \\
\hline
\end{tabular}

Médias seguidas de letras diferentes, minúsculas nas linhas e maiúsculas nas colunas, diferem pelo teste de Tukey a $5 \%$ de probabilidade. 
UFT/kg de ração e com 90 e $52 \%$ de Ca e $\mathrm{P}$, respectivamente, eram usadas, a densidade óssea era semelhante a das aves do tratamento controle. Entretanto, Orban et al. (1999) não constataram diferenças na densidade das diáfises tibiais devido à inclusão 750 ou 1500 UFT/kg de ração. Mais recentemente, Onyango et al. (2004) avaliaram níveis de FNF de 0,50, 0,24 e $0,12 \%$ e relataram que houve redução na densidade mineral das tíbias. Os autores, no entanto, observaram que a inclusão de 1000 UFT/kg de ração com $0,24 \%$ de FNF, elevou a densidade para valores similares aos obtidos com $0,50 \%$ de FNF.

\section{CONCLUSÕES}

Pode-se adotar dieta com níveis de FNF nas fases inicial, crescimento e final de $0,37,0,33$ e $0,29 \%$, respectivamente, suplementadas com 1000 UFT/kg de ração, no período de um a 42 dias de idade, sem que haja comprometimento da qualidade óssea dos frangos de corte.

\section{REFERÊNCIAS}

ANGEL, R.; SAYLOR, W.W.; MITCHELL, A.D. et al. Validation of dual X-ray absorptiometry (DXA) bone mineralization measures in broilers as an alternative to bone ash and breaking measures. Poultry Science, v. 83, Suppl. 1, p. 318, 2004.

ANGEL, R.; POWERS, W.; APPLEGATE, T.J. et al. Influence of phytase on watersoluble phosphorus in poultry and swine manure. Journal of Environmental Quality, v. 34, n. 2, p. 563-571, 2005a.

ANGEL, R.; SAYLOR, W.W.; DHANDU, A.S. et al. Effect of dietary phosphorus, phytase, and 25-hydroxycholecalciferol on performance of broiler chickens grown in floor pens. Poultry Science, v. 84, n.7, p. 1031-1044, 2005b.

APPLEGATE, T.J.; JOERN, B.C.;

NUSSBAUM-WAGLER, D.L. et al. Watersoluble phosphorus in fresh broiler litter is dependent upon phosphorus concentration fed but not on fungal phytase supplementation. Poultry Science, v. 82, n. 6, p. 1024-1029, 2003.

ATIA, F.A.; WAIBEL, P.E.; HERMES, I. et al. Effect of dietary phosphorus, calcium, and phytase on performance of growing turkeys. Poultry Science, v. 79, n. 2, p. 231-239, 2000.

BIEHL, R.R.; BAKER, D.H.; DELUCA, H.F. Activity of various hydroxylated vitamin $D_{3}$ analogs for improving phosphorus utilization in chicks receiving diets adequate in vitamin $\mathrm{D}_{3}$. British Poultry Science, v. 39, n. 3, p. 408-412, 1998.

DHANDU, A.S.; ANGEL, R. Broiler nonphytin phosphorus requirement in the finisher and withdrawal phases of a four phase feeding program. Poultry Science, v. 82, n. 8, p. 1257-1265, 2003.

DREZNER, M.K. Phosphorus homeostasis and related disorders. In: BILEZIKIAN, J.P.; RAISZ, L.G.; RODAN, G.A. Principles of Bone Biology, San Diego: Academic Press, 2002. p. 321-338.

HATTEN III, L.F.; INGRAM, D.R.; PITTMAN, S.T. Effect of phytase on production parameters and nutrient availability in broilers and laying hens - a review. Journal of Applied Poultry Research, v. 10, n. 3, p. 274-278, 2001.

JENDZA, J.A.; DILGER, R.N.; SANDS, J.S. et al. Efficacy and equivalency of an Escherichia coli-derived phytase for replacing inorganic phosphorus in the diets of broiler chickens and young pig. Journal of Animal Science, v. 84, n. 12, p. 33643374, 2006. 
JOAKIMSEN, R.M.; FONNEBO, V.; MAGNUS, J.H. et al. The Troms $\varnothing$ study: physical activity and the incidence of fractures in a middle-aged population. Journal of Bone and Mineral Research, v. 13, n. 7, p. 1149-1157, 1998.

KOCABAGLI, N. The effect of dietary phytase supplementation at different levels on tibial bone characteristics and strength in broilers. Turkish Journal of Veterinary Animal Science, v. 25, n. 5, p. 797-802, 2001.

LOUZADA, M.J.Q. Otimização da técnica de densitometria óptica em imagens radiográficas de peças ósseas. Estudo "in vitro". 1994, 191f. Campinas, Tese (Doutorado em Engenharia Elétrica) Universidade Estadual de Campinas.

NELSON, D.A.; BARONDESS, D.A.; HENDRIX, S.L. et al. Cross-sectional geometry, bone strength, and bone mass in the proximal femur in black and white postmenopausal women. Journal of Bone and Mineral Research, v. 15, n. 10, p. 1992-1997, 2000.

NATIONAL RESEARCH COUNCIL - NRC. Nutrient requirements of poultry. 8.ed., Washington: National Academy Press, 1994.

ONYANGO, E.M.; BEDFORD, M.R.; ADEOLA, $O$. The yeast production system in whick Escherichia coli phytase is expressed may affect growth performance, bone ash, and nutrient use in broiler chicks.

Poultry Science, v. 83, n. 3, p. 421-427, 2004.

ORBAN, J.I.; ADEOLA, O.; STROSHINE, $R$. Microbial phytase in finisher diets of White Pekin ducks: effect on growth performance, plasma phosphorus concentration, and leg bone characteristics. Poultry Science, v. 78, n. 3, p. 366-377, 1999.

PANDA, A.K.; RAO, S.V.R.; RAJU, M.V.L.N. et al. Performance of broiler chickens fed low non phytate phosphorus diets supplemented with microbial phytase. Journal of Poultry Science, v. 44, n. 3, p. 258-264, 2007.

ROSTAGNO, H.S.; ALBINO, L.F.T.; DONZELE, J.L. et al. Tabelas brasileiras para aves e suínos. Composição de alimentos e exigências nutricionais, Viçosa: UFV, 2005.

SHELTON, J.L.; SOUTHERN, L.L. Effects of phytase addition with or without a trace mineral premix on growth performance, bone response variables, and tissue mineral concentrations in commercial broilers. Journal of Applied Poultry Research, v.15, n.1, p. 94-102, 2006. UFV - Universidade Federal de Viçosa. SAEG - Sistema de análises estatísticas e genéticas. Versão 8.0. Viçosa, 2001.

UUSI-RASI, K.; SIEVANEN, H.; PASANEN, $M$. et al. Associations of calcium intake and physical activity with bone density and size in premenopausal and postmenopausal women: a peripheral quantitative computed tomography study. Journal of Bone and Mineral Research, v.17, n.3, p.544-552, 2002.

VIVEROS, A.; BRENES, A.; ARIJA, I. et al. Effects of microbial phytase supplementation on mineral utilization and serum enzyme activities in broiler chicks fed different levels of phosphorus. Poultry Science, v.81, n.8, p.1172-1183, 2002.

WU, Y.B.; RAVINDRAN, V.; MOREL, P.C.H. et al. Evaluation of a microbial phytase, produced by solid-state fermentation, in broiler diets. 1. Influence on performance, toe ash contents, and phosphorus equivalency estimates. Journal of Applied Poultry Research, v.13, n.3, p.373-383, 2004. 